\title{
The Prediction of Chronicity in Patients with Acute and Sub- Acute Non-Specific Low Back Pain and Associated Risk Factors: A Case-Control Study
}

\author{
Mohsen Sadeghi-Yarandi \\ Baqiyatallah University of Medical Sciences \\ Mohammad Ghasemi ( $D$ hse.expert2020@yahoo.com ) \\ Baqiyatallah University of Medical Sciences \\ Ali Ghanjal \\ Baqiyatallah University of Medical Sciences \\ Mojtaba Sepandi \\ Baqiyatallah University of Medical Sciences \\ Ahmad Soltanzadeh \\ Qom University of Medical Sciences
}

\section{Research Article}

Keywords: Chronic low back pain, Non-specific low back pain, Risk factor, Predictor, Path Analysis.

Posted Date: October 19th, 2021

DOl: https://doi.org/10.21203/rs.3.rs-971261/v1

License: (c) (i) This work is licensed under a Creative Commons Attribution 4.0 International License. Read Full License 


\section{Abstract}

Background: Chronic low back pain is one of the most common musculoskeletal disorders in different countries that people of any age can experience many times. This study aimed to predict the chronicity of non-specific acute and subacute LBP and related risk factors among cases referred to physiotherapy clinics.

Methods: This case-control study was performed among 420 patients suffered from acute, sub-acute and chronic LBP referred to two physiotherapy centers in Tehran-Iran in 2020. Data were obtained using the Fear-Avoidance Beliefs Questionnaire (FABQ), Patient Health Questionnaire (PHQ-9), Pain Catastrophic Scale (PCS-13), Tampa Scale for Kinesiophobia (TSK-11), Pittsburgh Sleep Quality Index (PSQI), Walker's Health-Promoting Lifestyle Questionnaire, Roland Morris Disability Questionnaire (RMDQ) and Numerical Pain Rating Scale (NPRS). Data analysis was performed by applying independent sample t-test, chi-square, and multiple logistic regression in SPSS software version 25. IBM Amos version 22 was employed for path analysis.

Results: The mean age and body mass index in all patients were $43.94 \pm 6.72$ years and $25.69 \pm 3.54 \mathrm{~kg} . \mathrm{m}^{-2}$, respectively. It was found that some demographic parameters (i.e. weight, BMI, job, type of occupational task performance, history of low back pain, work shift, underlying diseases and income), some cognitive parameters (i.e. fear-avoidance beliefs, kinesiophobia, catastrophic pain, and depression), some lifestyle parameters (i.e. health responsibility, physical activity and interpersonal relationships), sleep quality and pain related disability were among the most critical risk factors in the chronicity of acute and sub-acute LBP $(P<0.05)$.

Conclusion: Personal, psychological, and psychosocial parameters can be among the most critical predictors in the chronicity of acute and sub-acute non-specific LBP. Hence, paying attention to all the mentioned factors at the beginning of patients' treatment to create a targeted treatment algorithm and prevent the conversion of acute and sub-acute into chronic LBP has particular importance.

\section{Introduction}

Chronic low back pain (CLBP) is one of the most widespread and costly musculoskeletal disorders in different countries that people of any age can experience many times [1, 2]. According to the definition of the international association for the study of pain (IASP), the pain felt in the lumbar or sacral region of the spine is called low back pain (LBP) [3]. Previous studies have shown that the prevalence of LBP in adult population is more than $80 \%$ [4]. The highest rates of LBP disability in recent years have been reported in low- and middle-income countries like Asia and Africa countries, where investment in health and prevention is less important than treatment [5]. If the pain lasts less than seven days, it is entitled "acute", and if it lasts between seven days and three months, it is called "sub-acute". The presence of pain for more than three months is classified as "chronic" LBP [6]. Non-specific LBP represents a type of pain that the pathoanatomical cause cannot be identified and accounts for about 85 to $90 \%$ of all LBP and is usually felt in the lumbar spine, spreading in one or both thighs [7]. Studies have shown that in five to $30 \%$ of cases, acute and sub-acute LBP turns into chronic pain [8]. In Iran, LBP is one of the most prevalent issues, so that its prevalence among high school students, nurses, and pregnant women has been reported to be 17, 62, and 84 percent, respectively [7]. The overall prevalence of LBP in Iranian society has been reported between 14.4 to $84.1 \%$. LBP is also known as the third cause of the disease in $15-69$ years old in Iran [9].

Numerous studies have introduced different variables as risk factors affecting the prevalence of non-specific CLBP, which may vary depending on the study's objectives. These include demographic parameters, lifestyle, general health components, smoking, physical activity, medical facilities, occupational factors, psychological factors like fear-avoidance belief, fear of movement, stress, anxiety, depression, etc. $(2,10)$. Also, risk factors such as sleep disorders, resilience 
variables like optimism, social support, biophysical risk factors like body composition, etc., have rarely been studied in linked researches [11].

Psychological processes have a unique role in pain experience; however, psychological factors are not fully understood. The use of psychological knowledge in the treatment stages of patients is subject to challenge [12]. For example, parameters such as fear of movement, catastrophic pain, and the establishment of extreme beliefs about fear and avoidance of activity are among risk factors that can lead to limitation of activities, sedentary life, depression, and stress and eventually lead to CLBP $[13,14]$; therefore, proper and timely understanding of the exact role of each of these risk factors in the chronicity of LBP through predictive models in different communities can be a practical step in the implementation of proper planning for physical and psychological therapy of patients with acute and sub-acute nonspecific LBP [15].

Cohort studies have shown that cognitive factors exert a greater effect on non-specific LBP chronicity in some cases compared to biophysical factors [16]. It should be noted that predicting the results of LBP is not a simple process. It is common to utilize the information obtained from the initial evaluation to predict future clinical outcomes. Therefore, establishment of predictive models provides beneficial information for health professionals specially in occupational health settings. Hence, according to mentioned points, the importance of understanding actual risk factors affecting the chronicity of non-specific LBP, preventing the falling of acute and sub-acute LBP into chronic state, and also due to the lack of similar studies that consider the role of mentioned parameters as the underlying factors of CLBP to create practical predictive patterns, according to the different social, economic, medical and health conditions of developing countries compared to developed countries, the present study aimed to predict the chronicity of acute and sub-acute LBP and related risk factors among patients referred to physiotherapy clinics in Iran.

\section{Methods}

\section{Study design}

This case-control study was conducted from August to December 2020. The statistical population includes all patients referred to two physiotherapy centers (including two groups of patients with acute/sub-acute non-specific LBP as "control group" and chronic non-specific LBP as "case" group) in Tehran - Iran. The optimal sample size was determined at a level of 0.05 , and the desired power analysis of $80 \%$ with a $\beta$ level of $20 \%$ (according to previous studies and the mean of main variables). Accordingly, it was calculated to be at least 198 participants per group. Assuming a sample drop rate of $10 \%$, the final sample size was estimated as 436 individuals who were selected by convenience sampling method using inclusion criteria. Finally, according to the participants' response rate, 420 patients were studied (response rate: $96.33 \%$ ). A physiotherapist first examined patients for inclusion in the study. Four criteria were considered as inclusion criteria: 1) adults between 30 and 60 years with acute and sub-acute non-specific LBP, because of the similarities between the LBP patterns (including the presence of pain less than seven days in the lumbar vertebral column, buttocks, and lower limbs for acute patients and pain between 8 and 12 weeks for sub-acute patients), 2) adults between 30 and 60 years with chronic non-specific LBP (including pain between 3 to 6 months in the lumbar vertebrae, buttocks, and lower limbs), 3) ability to reading and writing Persian language and 4) sufficient satisfaction to participate in the study. Exclusion criteria also included: 1) the presence of systemic complications such as orthopedic, rheumatologic and inflammatory diseases, 2) history of cancer, 3 ) the presence of focal point tenderness on the spine, 4) history of structural spine problems, 5) history of the prolonged systemic use of corticosteroids, 6) spine fracture, osteoporosis, pregnancy, 7) history of spinal surgery, 8) history of major trauma to the spine (fall from a height, accident, sports incidents, etc.), 9) history of mental illness and 10) lack of sufficient satisfaction to participate in the study.

All the required information about the study's purpose was presented to the individuals, and informed consent form was signed by the participants. Patients were able to leave the study at any level if they did not satisfy. The ethics committee 
of the University of Medical Sciences approved the study's methodology, and the study was conducted following the Helsinki Declaration [17].

\section{Data collection}

All the studied parameters have been determined based on the review of valid scientific texts and experts' opinions. Demographic data were extracted using a self-administrated questionnaire, and to obtain the main variables, the following questionnaires were applied.

Fear-Avoidance Beliefs Questionnaire (FABQ): The FABQ was used to assess the extent of fear-avoidance beliefs [18]. This scale shows how much fear-avoidance beliefs affect patients' LBP. In this questionnaire, four items are related to physical activity (score range 0 to 24), and seven items are related to working activity (score range 0 to 42 ). Each item was scored using the Likert scale, from a score of zero "strongly disagree" to a score of 6 "strongly agree." High scores on both subscales indicate higher levels of fear-avoidance beliefs. This tool's validity and reliability have been confirmed in previous studies (Cronbach's alpha: 0.88) [19].

Patient Health Questionnaire (PHQ-9): The 9-item version of PHQ was used to assess depressive symptoms in patients with LBP. This questionnaire's score range is from 0 to 27, that high scores indicate higher levels of depression. Scores 1 to 4 indicate "minimal depression," scores 5 to 9 indicate "mild depression," scores 10 to 14 indicate "moderate depression," scores 15 to 19 indicate "moderately severe depression," and scores 20 to 27 indicate "severe depression" [20]. This tool's validity and reliability have been confirmed in previous studies [21].

Pain Catastrophizing Scale (PCS-13): Catastrophic pain is reflected to be a cognitive element of the pain fear process associated with pain-related disability in patients. This scale evaluates the range of patients' catastrophic thoughts and behaviors when faced with pain and consists of three subscales of mental rumination, exaggeration, and despair. Patients are asked to indicate how often they used each of the 13 phrases in this questionnaire when faced with pain based on their pain experience. The questionnaire is scored on a Likert scale with five options from zero "not at all" to four "all the time" range from zero to 52 as total score. Higher scores indicate more catastrophic pain [22]. This tool's validity and reliability have been confirmed in an Iranian research (Cronbach's alpha: 0.93) [23].

Tampa Scale of Kinesiophobia (TSK-11): The 11-item version of the TSK questionnaire was used to assess participants' fear of movement or re-injury. Kinesiophobia, or fear of movement, refers to an excessive, irrational, and debilitating fear of physical movement described as a result of a person's sense of vulnerability to re-injury [24]. The TSK-11 is an 11-item questionnaire with scores ranging from 11 to 44, that higher scores indicating greater fear of movement. Each item was scored using a Likert scale with four options, from a score of zero "strongly disagree" to three "strongly agree." This questionnaire's appropriate validity and reliability have been reported in an Iranian research (Cronbach's alpha: 0.80) [25].

Pittsburgh Sleep Quality Index (PSQI): The PSQI is a self-rated questionnaire that assesses sleep quality and disturbances over a 1-month time interval. This questionnaire has seven scales that include subjective sleep quality, sleep latency, sleep duration, habitual sleep efficiency (ratio of sleep duration to elapsed time in bed), sleep disturbances (waking up at night), use of sleeping medication, and daytime dysfunction (problems caused by insomnia during the day). The calculation of scores for these seven components yields one final score. Each scale's score is between zero to three, and the score of three on each scale indicates the maximum negative value. This questionnaire's overall score is between zero to 21 , and the overall score of 6 and above indicates the inadequate quality of sleep. This questionnaire's validity and reliability have been confirmed in several studies (Cronbach's alpha: 0.83) [26, 27].

Walker's health-promoting lifestyle Questionnaire: This questionnaire was first designed by Walker et al. and consists of 52 questions that measures six dimensions of spiritual growth, health responsibility, interpersonal relationships, stress management, physical activity, and nutrition with 8 or 9 questions. Each question has 4 Likert-scale answer options, 
including never, sometimes, most of the time, and always. The minimum score on this questionnaire is 52 , and the maximum is 208. High scores are indicating a better health-promoting lifestyle. A score of 52 to 104 is classified as a "poor lifestyle", a score of 105 to 156 is classified as an "average lifestyle", and a score of 157 to 208 is classified as a "good lifestyle" [28]. This tool's validity and reliability have been confirmed by Mohammadi Zeidi et al. in Iran (Cronbach's alpha 0.82) [29].

Roland-Morris Disability Questionnaire (RMDQ): In this questionnaire, the patient reads a series of phrases, and if it is right with the current condition of the patient, he/she marks in front of it. These expressions represent a wide range of daily activities that are disrupted by LBP. This questionnaire's total score is obtained by the sum of the number of marks that the patient has placed in front of each phrase (0 to 24). A higher score on this scale indicates greater physical disability [30]. This tool's validity and reliability have been confirmed in an Iranian research (Cronbach's alpha: 0.92) [31].

Numeric Pain Rating Scale (NPRS): Participants' pain intensity was assessed using a numerical pain scale from zero (no pain) to 10 (maximum pain intensity). This scale consists of a calibrated line in which expressions are used to describe each number. The patient marked the current, lowest and highest pain intensity experienced during the last 24 hours. The average of the three pain intensities was considered the individual's pain level [32]. The validity and reliability of this tool have been confirmed in Iran [33].

\section{Data analysis}

Data analysis was performed in SPSS software version 25.0 (SPSS Inc Chicago, Illinois). Kolmogorov-Smirnov test was used to check the normality of the data distribution. The normality test results revealed that the data distribution was normal in all cases $(P>0.05)$. Accordingly, to investigate the relationship between quantitative data and type of LBP, twoindependent sample t-test and to investigate the relationship between qualitative data and type of LBP, Chi-square test ( $\mathrm{X} 2$ ) was also used at a significance level of 0.05 . Equality of variances was also assessed using Levene's Test.

In first step, the multiple logistic regression model was used to predicting the chronicity of acute and sub-acute LBP. In this model, by eliminating the effect of confounding variables, the most significant risk factors in the chronicity of LBP are identified. For this purpose, based on the independent sample t-test and $\chi 2$ test results, variables significantly associated with the type of LBP were entered into the regression model. Then, to obtain the final regression model, the backward elimination method was used. In this method, all the independent parameters that effective in the chronicity of LBP were entered into the model. The less effective variables were removed step by step. The Nagelkerke and Cox \& Snell R-square were regarded as a measure for overall predictive performance. Calibration (i.e., the agreement between predicted and observed CLBP risks) was assessed by the Hosmer-Lemeshow goodness-of-fit test; $\mathrm{P} \geq 0.05$ indicates that predicted risks do not deviate significantly from observed risks, meaning that calibration is acceptable.

\section{Path Analysis}

In second step, path analysis was performed to predict the chronic LBP. In the present study, IBM SPSS Amos version 22.0 was employed for path analysis. Path analysis is a useful tool for assessing some direct and indirect effects of variables on a specific target variable, which was the chronicity of LBP in the present study. The strength of a path is described by a coefficient conceptually equal to standardized partial regression coefficients. A coefficient has a range from -1 to +1 . The higher the coefficient, the greater the effect one variable has on another. In addition to each path, the goodness of fit of a path analysis model can also be defined using indices available for such evaluations. These indices can be classified into two main groups: absolute fit indices and comparative fit indices. Absolute fit indices describe how well the hypothesized model fits the data. The model $\chi 2$ value, root mean square error of approximation (RMSEA), goodness-of-fit index (GFI), and root mean square residual (RMR) are some indices classified in this group. RMSEA is another absolute fit index recommended because of its sensitivity and informative and easy-to-interpret nature. This index is computed using the 
model $\chi 2$ value, $d f$, and sample size $(\mathrm{N})$. An RMSEA value lower than 0.07 indicates a good fit, values lower than 0.1 indicate mediocre fit, and values higher than 0.1 describe the unacceptable model fit [34].

\section{Results}

\section{Demographic parameters}

The mean age and BMI in all patients were $43.94 \pm 6.72$ years and $25.69 \pm 3.54 \mathrm{~kg} . \mathrm{m}^{-2}$, respectively. It was found that 49.5 percent (210 patients) had chronic LBP, and 50.5 percent ( 210 patients) had acute and sub-acute LBP. The study of the occupational task during working times showed that $30 \%$ of the participants have a sitting task, $31.9 \%$ have a standing task, $15.2 \%$ have manual material handling $(\mathrm{MMH}), 4.1 \%$ have exposure to whole-body vibration (WBV), and hand-arm vibration (HAV), $6.1 \%$ have repetitive movements and $12.7 \%$ have twisting and bending movements in the lumbar region. Other demographic characteristics are presented in Table 1. Examination of patients' demographic parameters according to type of LBP revealed that there was a significant difference between age, weight, BMI, job, work experience, working hours per day, type of work shift, education level, monthly income level, type of occupational task, history of previous LBP, history of underlying diseases and the type of LBP in the subjects $(P<0.05)($ Table 1$)$.

\section{Cognitive parameters}

The mean scores of fear-avoidance activities related to work (FABQ-W), fear beliefs - avoidance related to physical activity (FABQ-PA) and also, the total score of fear-avoidance beliefs (FABQ-Total) among patients with acute/subacute LBP were $26.94 \pm 0.16,18.18 \pm 0.13$ and $45.13 \pm 0.20$, respectively. Moreover, the above-mentioned parameters among patients with chronic LBP were $34.34 \pm 0.38,20.98 \pm 0.20$, and $55.33 \pm 0.45$, respectively.

Examination of depression levels among participants showed that $41.1 \%, 10.6 \%, 9.3 \%, 23.8 \%$, and $15.2 \%$ of patients were at minimal, mild, moderate, moderately severe, and severe levels of depression, respectively. Analysis of depression levels showed that all patients with acute/subacute LBP (100\%) were at low levels of depression, and $89.4 \%$ of patients with CLBP were at moderately severe and severe levels of depression.

The mean values of the pain catastrophizing scale among patients with acute/subacute and chronic LBP were $9.53 \pm 1.06$ and $32.46 \pm 4.15$, respectively. It was also found that the mean values of kinesiophobia among patients with acute/subacute and chronic LBP were $19.13 \pm 1.26$ and $34.72 \pm 3.49$, respectively. Ultimately, the present study's obtained findings demonstrated that the mean values of all cognitive parameters; Including fear-avoidance beliefs, depression, pain catastrophizing, and kinesiophobia were at much higher levels in patients with CLBP compared to other patients. Also, statistical analysis showed that there was a significant relationship between the values of all cognitive parameters and the type of LBP $(P<0.05)$ (Table 2).

\section{Sleep quality components}

The average score of PSQI among all patients was 13.68 \pm 3.79 . The average sleeping hours per day among all subjects was $5.81 \pm 1.32$ hours. The results showed that the average score of all sleep quality components except subjective sleep quality was at higher levels among patients with CLBP (compared to acute/subacute LBP). The average score of PSQI among patients with acute/subacute and chronic LBP were $10.25 \pm 0.16$ and $16.78 \pm 0.33$, respectively. Other values of sleep quality components according to the type of LBP are presented in Table 3. Considering the cut point of six for the border of low sleep quality, it was found that $95 \%$ of participants have undesirable sleep quality (Table 3 ).

\section{Lifestyle components}

The mean lifestyle score among all the participants was $123.58 \pm 28.68$. It was indicated that $40.4 \%$ of the participant had a poor lifestyle, $49.7 \%$ had moderate, and $9.9 \%$ had a good and favorable lifestyle. The average score of lifestyle among 
patients with acute/subacute and chronic LBP were $140.67 \pm 1.01$ and $104.12 \pm 3.04$, respectively. It was also observed that the dimensions of spiritual growth, interpersonal relationships, physical activity, and nutrition were lower in patients with CLBP. Among patients with acute/subacute LBP, $80 \%$ had a poor lifestyle, and $20 \%$ had a favorable lifestyle level. Among patients with chronic LBP, $72.7 \%$ had a poor lifestyle, $16.7 \%$ had a moderate lifestyle, and $10.6 \%$ had a favorable lifestyle level. There was also a significant relationship between the dimensions of spiritual growth, health responsibility, interpersonal relationships, stress management, physical activity, nutrition and overall lifestyle score and type of LBP (P $<0.05$ ) (Table 4).

\section{Disability and pain intensity}

The evaluation of disability and pain intensity indices showed that the mean value of the two mentioned indices among all participants was $13.70 \pm 7.39$ and $5.98 \pm 1.74$, respectively. The mean disability index among patients with acute/subacute and chronic LBP was $7.46 \pm 0.57$ and $20.48 \pm 0.56$, respectively. The mean numerical pain intensity index among the mentioned patients was $5.44 \pm 0.14$ and $7.46 \pm 0.18$, respectively. There was a significant correlation between the type of LBP and the mean score of two indicators of disability and pain intensity $(P<0.05)$. The mean values of disability and pain intensity were much higher among patients with CLBP. The majority of patients with acute/subacute LBP (53.4\%) reported mean numerical pain intensity of "five," and the majority of patients with CLBP (37.9\%) reported mean numerical pain intensity of "eight."

\section{Multiple Logistic Regression Model}

Table 5 shows the most important risk factors for chronicity of acute and sub-acute non-specific LBP based on a modified multiple logistic regression model. The values of Negelkerke and Cox \& Snell $R^{2}$ of the model were 0.957 and 0.846 , respectively.

\section{Path Analysis Model}

The path analysis model revealed that lifestyle, disability, pain intensity, sleep quality, depression, and fear-avoidance beliefs are among the most important predictors of chronic LBP. Lifestyle indirectly predicts CLBP and apply large effects on the parameters of disability, pain intensity, sleep quality, depression, and fear-avoidance beliefs. other parameters can directly affect and predict the chronicity of LBP. The model fit indices and standardized path coefficients, and significant level are presented in Tables 6 and 7. The final obtained path analysis model is presented in Figure 1.

\section{Discussion}

CLBP was responsible for the creation of 60.1 million disability-adjusted life-years (DALY) in 2015. Since 1990, with a 54\% increase, it has the highest prevalence in low- and middle-income countries [33]. Examination of patients' demographic parameters demonstrated that there was a significant relationship between age, BMI, job, work experience, working hours per day, type of work shift, education level, monthly income, type of occupational task, previous LBP, history of underlying diseases and type of LBP in the subjects (Table 1). Previous studies have shown that these parameters are among the influencing factors in the chronicity of LBP $[2,35]$. It has been found that patients with older ages, higher BMI, higher working hours, and jobs with higher workload are at higher risk of CLBP [36,37]. Previous studies have shown that income levels are also an important factor in preventing CLBP, and people with higher incomes are likely to be in better lifestyle status and have a lower risk of CLBP [35], which is consistent with the findings of the present study. A history of previous LBP is also a crucial factor in the chronicity of LBP. So that if the patient has not been appropriately treated in the past, the pain has entered into the chronic phase, and in the case of recurrence of LBP, the person is entirely prone to CLBP. It was also found that a history of underlying diseases can affect the patient psychologically and physiologically dimensions and facilitate the chronicity of LBP [35]. Shift work schedule was also an important factor in the LBP chronicity. Perhaps 
the reason can be found in the decrease in sleep quality. A higher percentage of patients with CLBP were working at night and shift work, compared to patients with acute and sub-acute LBP.

Among patients with CLBP the mean score of fear-avoidance beliefs about work activities (FABQ-W) and fear-avoidance beliefs about physical activity (FABQ-PA) was significantly higher than patients with acute/subacute LBP (Table 2). The study by Woby et al. showed that as people's self-efficacy decreases due to LBP, fear of movement and avoidant behaviors increase, which can lead to CLBP. Also, reducing fear-avoidance beliefs concerning work activities and physical activity leads to increased self-control against pain and disability. It can be a useful step in preventing the CLBP [38]. Chung et al. Also showed that fear-avoidance beliefs are an important factor in the chronicity of LBP and related disability that is in line with the findings of the present study [39].

The rate of depression among patients with CLBP was significantly higher than patients with acute and subacute LBP (Table 2). The study conducted by Cougot et al. revealed that depression is an important factor in CLBP and long absences from work [40]. The study by Shmagel et al. also demonstrated that a high percentage of patients with CLBP were in severe and very severe depression levels, which is consistent with the findings of the present study [35]. Depression, stress, and anxiety are risk factors and a consequence for the chronicity of LBP and lead to a decrease in the treatment process's efficiency [2]. Depression severely affects a patient's life quality, reduces physical activity, increases the risk of a variety of mental illnesses, and in some patients can lead to refusal to continue treatment $[2,10]$.

The catastrophic rate of pain in patients with CLBP was significantly higher compared to the control group. Individuals with acute and sub-acute LBP, due to their pain's destructive nature, imagine it more intensely, exert more physical and psychological pressure on themselves, and thus pave the way for chronicity of LBP. It is quite probable that patients engage in pain avoidance behaviors and are always waiting for the occurrence of pain in response to the fear of catastrophic pain and in an attempt to control the painful event that may occur in the future. Many empirical studies have shown that catastrophic pain is directly associated with CLBP, which is consistent with the present study [2, 41]. The mean value of kinesiophobia among patients with CLBP is much higher than other patients. Previous studies have shown a direct and significant relationship between psychological factors such as kinesiophobia and catastrophic pain, and chronicity of acute and sub-acute LBP, which is in line with the present study findings $[2,13]$. Some studies have explicated that in many cases, fear of movement and pain can be more debilitating than pain and accelerates LBP chronicity [41]. In general, it can be claimed that all three parameters of kinesiophobia, catastrophic pain, and fear-avoidance beliefs are closely related to each other, and each parameter can accelerate the process of LBP chronicity.

The sleeping hours of patients with CLBP were shorter than control group, which was rooted in their pain. The results explained that the mean score of all sleep quality components except subjective sleep quality among patients with CLBP was higher (Table 3). The mean total score of sleep quality among patients with CLBP was higher than control group, which indicates poor sleep quality among them and can lead to more psychological and physical stress and as a result, the chronicity process of LBP can be facilitated [35]. It can be explained that patients with CLBP have more delayed sleep, shorter sleep duration, more sleep disturbances, and higher use of sedative medication compared to other patients. Previous studies have shown that the quality of sleep among patients with CLBP was significantly lower than patients with acute LBP, and sleep is one of the effective parameters in the chronicity of LBP, which was compatible with the present research [2].

The score of some lifestyle components like spiritual growth, interpersonal relationships, physical activity, and nutrition in patients with CLBP was lower than other patients (Table 4). The obtained results indicate that patients with acute and subacute LBP are more sensitive to their health status due to the shorter LBP duration (less than three months) and have more social interactions and interpersonal relationships. Despite the presence of pain, they had more physical activity and better nutritional status than patients with CLBP. Furthermore, patients with CLBP have experienced more pain tolerance because they have struggled with pain for a more extended time and have generally been more successful in managing 
the stress caused by their pain. Finally, it was noticed that patients with acute and sub-acute LBP had a better lifestyle, which is consistent with previous studies' results $[28,42]$. Previous studies have revealed that increasing muscle strength through light exercise can help support the spine. Improving the flexibility of the muscles, tendons, and ligaments of the back increases the range of motion and help improve patient function. Aerobic exercise also increases blood flow and nutrients to the back's soft tissues and accelerates the healing process [43]. There is a significant relationship between the degree of disability, depression, anxiety, and lifestyle levels of patients, and lifestyle is a strong predictor for LBP chronicity [13].

Brox et al. also revealed that the rate of disability in patients with CLBP was significantly higher than acute and sub-acute cases. The degree of disability is an important predictor for LBP chronicity, which is consistent with the present study results [44]. The disability and severity of pain are both a risk factor and a consequence of LBP, which can be subjective or objective. In both cases, it can lead to a variety of physical and psychosocial problems and eventually CLBP.

The regression model explicated that weight, BMI, job, type of occupational task, previous LBP, work shifts, underlying diseases, income, fear-avoidance beliefs, Kinesiophobia, pain catastrophizing, depression, health responsibility, physical activity, interpersonal relationships, sleep duration, sleep disturbances, sleep quality, and patients' disability are among the most important risk factors in the chronicity of LBP. These findings indicate that LBP is a complex and multifactorial phenomenon that different pathologic, anatomic, neurophysiologic, physical, and psychologic factors are influential in its development and chronicity.

The path analysis model revealed that lifestyle indirectly predicts CLBP and avoids large effects on the parameters of disability, pain intensity, sleep quality, depression, and fear-avoidance beliefs, and other parameters can directly affect and predict the chronicity of LBP. Depression was the most important predictor of CLBP with a standardized path coefficient of 0.68 (Figure 1).

Among the strengths of the present study we can point out the evaluation and modeling the wide range of individual, psychological, psychosocial, and physical parameters in the development of CLBP for the first time in Iran. Our findings can create a novel insight into various risk factors affecting the chronicity of acute and sub-acute LBP. The present study can be a practical step towards establishing a targeted treatment plan and also preventing the chronicity of LBP. The cost of treatment and healthcare systems differ considerably from country to country and are influenced by local health, treatment, and social systems. CLBP and its associated costs are projected to increase in the coming decades, especially in low- and middle-income countries such as Iran, where health care systems are often somewhat hard to access in case of critical situations (like coronavirus pandemic) and have fewer financial resources. Therefore, global research efforts and initiatives are needed to reduce LBP and prevent the chronicity of LBP as an important and crucial public health problem.

Among the limitations of the present study it can be noted as: the impossibility of conducting a prospective cohort study and examining the trend of changes in various physical, psychological, and psychosocial parameters during the therapeutic interventions, and evaluating the effectiveness of intervention measures. Also, during the present study, temporal relationships or causal inferences between different risk factors were not investigated. Therefore, it is suggested that in the future, researchers will conduct prospective studies with appropriate physical and psychological clinical interventions and also report the effectiveness of each intervention.

\section{Conclusion}

The results of the present study revealed that demographic and individual risk factors as well as parameters such as the level of fear-avoidance beliefs, fear of movement (kinesophobia), catastrophic pain, depression, lifestyle, sleep quality, disability, and pain intensity are among important parameters and risk factors in the chronicity of acute and sub-acute

Page 9/19 
LBP. Therefore, paying attention to all the mentioned aspects at the beginning of treatment of patients with acute and subacute non-specific LBP to improve the treatment process, generate a meaningful treatment algorithm in order to prevent the typical clinical scenario of a conversion of acute and sub-acute into chronic low back pain.

\section{Abbreviations}

LBP: Low Back Pain

CLBP: Chronic Low Back Pain

FABQ: Fear-Avoidance Beliefs Questionnaire

PHQ-9: Patient Health Questionnaire

PCS-13: Pain Catastrophic Scale

TSK-11: Tampa Scale for Kinesiophobia

PSQI: Pittsburgh Sleep Quality Index

RMDQ: Roland Morris Disability Questionnaire

NPRS: Numerical Pain Rating Scale

\section{Declarations}

\section{Authors' contributions}

Mohsen Sadeghi-Yarandi collected the data, drafted and edited the manuscript. Ali Ghanjal and Mojtaba Sepandi performed statistical analysis and interpretation of data. Ahmad Soltanzadeh performed statistical modeling and path analysis. Mohammad Ghasemi performed critical reversion of manuscript for important intellectual content, administrative and technical support. All authors read and approved the final manuscript.

\section{Funding}

There were no sources of funding for this study.

\section{Availability of data and materials}

The datasets analyzed during the current study are available from the corresponding author.

\section{Ethics approval and consent to participate}

This article is the result of a research project with the ethics code of IR.BMSU.REC.1399.364 which was approved by Baqiyatallah University of Medical Sciences. All the required information about the study's purpose was presented to the individuals, and informed consent form was signed by the participants. Patients were able to leave the study at any level if they did not satisfy. The ethics committee of the University of Medical Sciences approved the study's methodology, and the study was conducted following the Helsinki Declaration

\section{Consent for publication}

All participants were given the opportunity to opt out of provision of their data if they did not wish a manuscript including their data to be published. 


\section{Competing interests}

The authors declare that they have no competing interests.

\section{Acknowledgment}

This article is the result of a research project with the ethics code of IR.BMSU.REC.1399.364 which was approved by Baqiyatallah University of Medical Sciences. Therefore, the authors would like to express their special thanks to Baqiyatallah University of Medical Sciences as well as the participants and clinical staff of the studied clinics for their contribution to the present study.

\section{References}

1. Ghasemi M, Khoshakhlagh AH, Ghanjal A, Yazdanirad S, Laal F. The impacts of rest breaks and stretching exercises on lower back pain among commercial truck drivers in Iran. International journal of occupational safety and ergonomics. 2020;26(4):662-9.

2. Boissoneault J, Mundt J, Robinson M, George SZ. Predicting low back pain outcomes: suggestions for future directions. journal of orthopaedic \& sports physical therapy. 2017;47(9):588-92.

3. Malliou P, Gioftsidou A, Beneka A, Godolias G. Measurements and evaluations in low back pain patients. Scandinavian journal of medicine \& science in sports. 2006;16(4):219-30.

4. Balagué F, Mannion AF, Pellisé F, Cedraschi C. Non-specific low back pain. The lancet. 2012;379(9814):482-91.

5. Hoy DG, Smith E, Cross M, Sanchez-Riera L, Blyth FM, Buchbinder R, et al. Reflecting on the global burden of musculoskeletal conditions: lessons learnt from the global burden of disease 2010 study and the next steps forward. Annals of the rheumatic diseases. 2015;74(1):4-7.

6. Morris P, Ali K, Merritt M, Pelletier J, Macedo LG. A systematic review of the role of inflammatory biomarkers in acute, subacute and chronic non-specific low back pain. BMC musculoskeletal disorders. 2020;21(1):1-12.

7. Ramezani M, Taghizade G, Abdolvahab M, Lajavardi L, Saeidi Brojeni M. Investigating of risk factors related to chronic non-specific low back pain in military men. Journal of Modern Rehabilitation. 2015;9(3):54-63.

8. Manchikanti L, Singh V, Datta S, Cohen SP, Hirsch JA. Comprehensive review of epidemiology, scope, and impact of spinal pain. Pain physician. 2009;12(4):E35-70.

9. Mousavi SJ, Akbari ME, Mehdian H, Mobini B, Montazeri A, Akbarnia B, et al. Low back pain in Iran: a growing need to adapt and implement evidence-based practice in developing countries. Spine. 2011;36(10):E638-E46.

10. Pinheiro MB, Ferreira ML, Refshauge K, Maher CG, Ordoñana JR, Andrade TB, et al. Symptoms of depression as a prognostic factor for low back pain: a systematic review. The Spine Journal. 2016;16(1):105-16.

11. Gheldof EL, Vinck J, Vlaeyen JW, Hidding A, Crombez G. Development of and recovery from short-and long-term low back pain in occupational settings: a prospective cohort study. European Journal of Pain. 2007;11(8):841-54.

12. Yadollahpour N, Zahednejad S, Yazdi MJS, Esfandiarpour F. The Discriminant Ability of Physical and Psychological Factors in Stratification of Patients with Low Back Pain Based on Start Back Screening Tool. J Biochem Tech. 2019;:Special Issue(2):168-74.

13. Alhowimel A, AlOtaibi M, Radford K, Coulson N. Psychosocial factors associated with change in pain and disability outcomes in chronic low back pain patients treated by physiotherapist: a systematic review. SAGE open medicine. 2018;6:2050312118757387.

14. Wertli MM, Rasmussen-Barr E, Held U, Weiser S, Bachmann LM, Brunner F. Fear-avoidance beliefs-a moderator of treatment efficacy in patients with low back pain: a systematic review. The Spine Journal. 2014;14(11):2658-78. 
15. Mehling W, Avins A, Acree M, Carey T, Hecht F. Can a back pain screening tool help classify patients with acute pain into risk levels for chronic pain? European journal of pain. 2015;19(3):439-46.

16. Bogduk N. Psychology and low back pain. International Journal of Osteopathic Medicine. 2006;9(2):49-53.

17. Goodyear MD, Krleza-Jeric K, Lemmens T. The declaration of Helsinki. British Medical Journal Publishing Group; 2007.

18. Waddell G, Newton M, Henderson I, Somerville D, Main CJ. A Fear-Avoidance Beliefs Questionnaire (FABQ) and the role of fear-avoidance beliefs in chronic low back pain and disability. Pain. 1993;52(2):157-68.

19. Rostami M, Noorian N, Mansournia MA, Sharafi E, Babaki AES, Kordi R. Validation of the Persian version of the fear avoidance belief questionnaire in patients with low back pain. Journal of back and musculoskeletal rehabilitation. 2014;27(2):213-21.

20. Löwe B, Kroenke K, Herzog W, Gräfe K. Measuring depression outcome with a brief self-report instrument: sensitivity to change of the Patient Health Questionnaire (PHQ-9). Journal of affective disorders. 2004;81(1):61-6.

21. Dadfar M, Kalibatseva Z, Lester D. Reliability and validity of the Farsi version of the Patient Health Questionnaire-9 (PHQ-9) with Iranian psychiatric outpatients. Trends in psychiatry and psychotherapy. 2018;40(2):144-51.

22. Sullivan MJ, Bishop SR, Pivik J. The pain catastrophizing scale: development and validation. Psychological assessment. 1995;7(4):524.

23. Mohamadi S, Dehghani M, Heidari M, Sedaghat M, Khatibi A. The evaluation of pain-related psychological similarities among patients with musculoskeletal chronic pain and their spouses. International Journal of Behavioral Sciences. 2013;7(1):57-66.

24. Silver A, Haeney M, Vijayadurai P, Wilks D, Pattrick M, Main C. The role of fear of physical movement and activity in chronic fatigue syndrome. Journal of psychosomatic research. 2002;52(6):485-93.

25. Jafari H, Ebrahimi I, Salavati M, Kamali M, Fata L. Psychometric properties of Iranian version of Tampa Scale for Kinesiophobia in low back pain patients. Archives of Rehabilitation. 2010;11(1):0-.

26. Mansouri A, Mokhayeri Y, Mohammadi Farrokhran E, Tavakkol Z, Fotouhi A. Sleep quality of students living in dormitories in Tehran University of Medical Sciences (TUMS) in 2011. Iranian Journal of Epidemiology. 2012;8(2).

27. Moghaddam JF, Nakhaee N, Sheibani V, Garrusi B, Amirkafi A. Reliability and validity of the Persian version of the Pittsburgh Sleep Quality Index (PSQI-P). Sleep and Breathing. 2012;16(1):79-82.

28. Sadeghi Yarandi M, Ghasemi M, Ghanjal A. The relationship between individual, physical and psychosocial risk factors with musculoskeletal disorders and related disabilities in flight security personnel. International journal of occupational safety and ergonomics. 2020:1-11.

29. Mohammadi Zeidi I, Pakpour Hajiagha A, Mohammadi Zeidi B. Reliability and validity of Persian version of the healthpromoting lifestyle profile. Journal of Mazandaran University of Medical Sciences. 2012;21(1):102-13.

30. Roland M, Fairbank J. The Roland-Morris disability questionnaire and the Oswestry disability questionnaire. Spine. 2000;25(24):3115-24.

31. Asghari M, Golak N. The roles of pain coping strategies in adjustment to chronic pain. Clinical Psychology and Personality. 2005;3(1):1-23.

32. Childs JD, Piva SR, Fritz JM. Responsiveness of the numeric pain rating scale in patients with low back pain. Spine. 2005;30(11):1331-4.

33. Nakhostin Ansari N, Naghdi S, Habibzadeh F, Salsabili N, Ebadi S. Persian translation and validation of the Back Pain Functional Scale. Physiotherapy theory and practice. 2018;34(3):223-30.

34. Hooper D, Coughlan J, Mullen M, Hooper D. Structural equation modelling: Guidelines for determining model fit. Electron J Bus Res Methods. 2008; 6 (1): 53-60. 
35. Shmagel A, Foley R, Ibrahim H. Epidemiology of chronic low back pain in US adults: data from the 2009-2010 National Health and Nutrition Examination Survey. Arthritis care \& research. 2016;68(11):1688-94.

36. Akbari H, Akbari H, Bagheri Hossein Abadi M, Gholami Fesharaki M, Ghasemi M. Assessing the risk of manual handling of patients and its relationship with the prevalence of musculoskeletal disorders among nursing staff: Performance evaluation of the MAPO and PTAI methods. Iranian Red Crescent Medical Journal. 2017;19(2).

37. Ahmadi H, Farshad A, Motamedzadeh M, Mahjob H. Epidemiology of low-back pain and its association with occupational and personal factors among employees of Hamadan province industries. Journal of Health. 2014;5(1):59-66.

38. Woby SR, Urmston M, Watson PJ. Self-efficacy mediates the relation between pain-related fear and outcome in chronic low back pain patients. European Journal of Pain. 2007;11(7):711-8.

39. Chung EJ, Hur Y-G, Lee B-H. A study of the relationship among fear-avoidance beliefs, pain and disability index in patients with low back pain. Journal of exercise rehabilitation. 2013;9(6):532.

40. Cougot B, Petit A, Paget C, Roedlich C, Fleury-Bahi G, Fouquet M, et al. Chronic low back pain among French healthcare workers and prognostic factors of return to work (RTW): a non-randomized controlled trial. Journal of Occupational Medicine and Toxicology. 2015;10(1):1-15.

41. Woby SR, Watson PJ, Roach NK, Urmston M. Adjustment to chronic low back pain-the relative influence of fearavoidance beliefs, catastrophizing, and appraisals of control. Behaviour research and therapy. 2004;42(7):761-74.

42. Hartvigsen J, Hancock MJ, Kongsted A, Louw Q, Ferreira ML, Genevay S, et al. What low back pain is and why we need to pay attention. The Lancet. 2018;391(10137):2356-67.

43. Gordon R, Bloxham S, editors. A systematic review of the effects of exercise and physical activity on non-specific chronic low back pain. Healthcare; 2016: Multidisciplinary Digital Publishing Institute.

44. Brox JI, Storheim K, Holm I, Friis A, Reikeras O. Disability, pain, psychological factors and physical performance in healthy controls, patients with sub-acute and chronic low back pain: a case-control study. Journal of Rehabilitation Medicine. 2005;37(2):95-9.

\section{Tables}

Table 1 - Values of demographic parameters of patients $(n=502)$ 


\begin{tabular}{|c|c|c|c|c|c|}
\hline \multirow[t]{2}{*}{ Parameter } & & \multirow{2}{*}{$\begin{array}{l}\text { All } \\
\text { participants } \\
(n=420)\end{array}$} & \multicolumn{2}{|l|}{ Type of LBP } & \multirow{2}{*}{$\begin{array}{l}\mathrm{P} \text { - } \\
\text { value }\end{array}$} \\
\hline & & & $\begin{array}{l}\text { Chronic } \\
(n=210)\end{array}$ & $\begin{array}{l}\text { Acute/Sub- } \\
\text { acute } \\
(n=210)\end{array}$ & \\
\hline \multicolumn{2}{|l|}{ Age (years) $(\mathrm{M} \pm \mathrm{SD})$} & $43.94 \pm 6.72$ & $46.5 \pm 0.80$ & $42.00 \pm 0.85$ & $0.001^{*}$ \\
\hline \multicolumn{2}{|l|}{ Body Mass Index (Kg.m $\left.\mathrm{m}^{-2}\right)(\mathrm{M} \pm \mathrm{SD})$} & $25.69 \pm 3.54$ & $26.82 \pm 0.40$ & $24.57 \pm 0.49$ & $0.001^{*}$ \\
\hline \multirow[t]{2}{*}{ Gender (percentage) } & Male & 63.6 & 57.6 & 67.2 & \multirow[t]{2}{*}{0.387} \\
\hline & Female & 36.4 & 42.4 & 32.8 & \\
\hline \multirow[t]{2}{*}{ Marital status (percentage) } & Married & 86.1 & 87.9 & 82.8 & \multirow[t]{2}{*}{0.074} \\
\hline & Single & 13.9 & 12.1 & 17.2 & \\
\hline \multirow[t]{4}{*}{ Job (percentage) } & Homemakers & 13.3 & 12.1 & 13.8 & \multirow[t]{4}{*}{$0.003^{*}$} \\
\hline & Employee & 44 & 39 & 45.9 & \\
\hline & Self-employment & 19.9 & 13.6 & 29.3 & \\
\hline & Retired & 22.8 & 35.3 & 11 & \\
\hline \multicolumn{2}{|l|}{ Work experience (years) $(\mathrm{M} \pm \mathrm{SD})$} & $12.47 \pm 6.67$ & $15.98 \pm 1.44$ & $10.25 \pm 0.75$ & $0.008^{*}$ \\
\hline \multicolumn{2}{|l|}{ Working hours per day $(\mathrm{M} \pm S \mathrm{~S})$} & $6.66 \pm 2.95$ & $6.77 \pm 0.49$ & $6.37 \pm 0.35$ & $0.049^{*}$ \\
\hline \multirow[t]{3}{*}{ Work Shift (percentage) } & Day work & 69.4 & 55 & 79 & \multirow[t]{3}{*}{$0.001^{*}$} \\
\hline & Night work & 24.2 & 30 & 21 & \\
\hline & $\begin{array}{l}\text { Work shift } \\
\text { (Rotational) }\end{array}$ & 6.4 & 15 & 0 & \\
\hline \multirow[t]{3}{*}{ Education level (percentage) } & Diploma and lower & 42.3 & 51.8 & 25.9 & \multirow[t]{3}{*}{$0.027^{\star}$} \\
\hline & Associate Degree & 29.5 & 34.8 & 31 & \\
\hline & Bachelor and higher & 28.2 & 13.4 & 43.1 & \\
\hline \multirow[t]{3}{*}{ Monthly income (percentage) } & $<40$ million (Rials) & 58.3 & 78.8 & 43.1 & \multirow[t]{3}{*}{$0.032^{*}$} \\
\hline & $40-80$ million (Rials) & 33.8 & 21.2 & 40.9 & \\
\hline & $>80$ million (Rials) & 7.9 & 0 & 16 & \\
\hline \multirow{6}{*}{$\begin{array}{l}\text { Type of occupational task } \\
\text { (percentage) }\end{array}$} & Sitting & 30 & 15.9 & 37.9 & \multirow[t]{6}{*}{$0.001^{*}$} \\
\hline & Standing & 31.9 & 39.4 & 32.3 & \\
\hline & MMH & 15.2 & 27.9 & 8.9 & \\
\hline & WBV and HAV & 4.1 & 4.2 & 4.3 & \\
\hline & $\begin{array}{l}\text { Repetitive } \\
\text { movements }\end{array}$ & 6.1 & 6.9 & 5.5 & \\
\hline & $\begin{array}{l}\text { Twisting and } \\
\text { bending }\end{array}$ & 12.7 & 5.6 & 11.1 & \\
\hline Previous LBP (percentage) & Yes & 43 & 60.6 & 24.1 & $0.001^{*}$ \\
\hline
\end{tabular}




\begin{tabular}{|c|c|c|c|c|c|}
\hline & No & 57 & 39.4 & 75.9 & \\
\hline \multirow[t]{6}{*}{ Underlying diseases (percentage) } & No & 45.1 & 31.8 & 55.2 & \multirow[t]{6}{*}{$0.020^{*}$} \\
\hline & $\begin{array}{l}\text { Cardiovascular } \\
\text { diseases }\end{array}$ & 19.9 & 18.2 & 22.4 & \\
\hline & Kidney diseases & 13.2 & 19.7 & 8.6 & \\
\hline & Pulmonary diseases & 17.9 & 22.7 & 13.8 & \\
\hline & Liver diseases & 0.8 & 1.5 & 0 & \\
\hline & Other & 3.1 & 6.1 & 0 & \\
\hline
\end{tabular}

LBP: Low Back Pain, MMH: Manual Material Handling, WBV: Whole-Body Vibration, HAV: Hand-Arm Vibration ${ }^{*} p<0.05$

Table 2 - Values of cognitive risk factors among the studied subjects $(n=502)$

\begin{tabular}{|c|c|c|c|c|c|c|c|}
\hline \multirow[t]{3}{*}{ Parameter } & \multirow{2}{*}{\multicolumn{2}{|c|}{ All participants $(n=420)$}} & \multicolumn{4}{|c|}{ Type of LBP } & \multirow[t]{3}{*}{ P-value } \\
\hline & & & \multicolumn{2}{|c|}{ Chronic $(n=210)$} & \multicolumn{2}{|c|}{ Acute/Sub-acute $(n=210)$} & \\
\hline & $M$ & $S D$ & $M$ & $S D$ & $M$ & $S D$ & \\
\hline FABQ-PA & 19.48 & 3.31 & 20.98 & 0.20 & 18.18 & 0.13 & $0.0001^{*}$ \\
\hline FABQ-W & 29.00 & 6.19 & 34.34 & 0.38 & 26.94 & 0.16 & $0.0001^{*}$ \\
\hline FABQ-Total & 47.49 & 9.18 & 55.33 & 0.45 & 45.13 & 0.20 & $0.0001^{*}$ \\
\hline PHQ-9 & 14.93 & 8.32 & 18.21 & 0.48 & 12.43 & 2.44 & $0.0001^{*}$ \\
\hline PCS-13 & 24.09 & 15.49 & 32.46 & 4.15 & 9.53 & 1.06 & $0.0001^{*}$ \\
\hline TSK-11 & 28.51 & 8.63 & 34.72 & 3.49 & 19.13 & 1.26 & $0.0001^{*}$ \\
\hline
\end{tabular}

FABQ-PA: Fear-Avoidance Beliefs Questionnaire (Physical Activity), FABQ-W: Fear-Avoidance Beliefs Questionnaire (Work), FABQ-Total: Fear-Avoidance Beliefs Questionnaire (Total Score), PHQ-9: Patient Health Questionnaire (Depression), PCS13: Pain Catastrophizing Scale, TSK-11: Tampa Scale of Kinesiophobia

${ }^{*} p<0.05$

Table 3 - Sleep quality score values among the studied patients $(n=502)$ 


\begin{tabular}{|c|c|c|c|c|c|c|c|c|}
\hline \multirow[t]{3}{*}{ Dimensions } & & \multirow{2}{*}{\multicolumn{2}{|c|}{$\begin{array}{l}\text { All participants } \\
(n=420)\end{array}$}} & \multicolumn{4}{|c|}{ Type of LBP } & \multirow[t]{3}{*}{ P-value } \\
\hline & & & & \multicolumn{2}{|c|}{$\begin{array}{l}\text { Chronic } \\
(n=210)\end{array}$} & \multicolumn{2}{|c|}{$\begin{array}{l}\text { Acute/Sub-acute } \\
(n=210)\end{array}$} & \\
\hline & & $M$ & $S D$ & $M$ & $S D$ & $M$ & $S D$ & \\
\hline Sleeping hours per day & & 5.81 & 1.32 & 5.11 & 1.10 & 6.29 & 1.71 & $0.031^{*}$ \\
\hline Subjective sleep quality & & 2.22 & 0.48 & 1.80 & 0.05 & 2.51 & 0.06 & $0.0001^{*}$ \\
\hline Sleep latency & & 1.80 & 0.74 & 2.36 & 0.07 & 1.22 & 0.05 & $0.0001^{*}$ \\
\hline Sleep duration & & 1.41 & 1.07 & 1.80 & 0.10 & 1.11 & 0.12 & $0.0001^{*}$ \\
\hline Habitual sleep efficiency & & 1.86 & 0.85 & 2.30 & 0.89 & 1.51 & 0.10 & $0.0001^{*}$ \\
\hline Sleep disturbances & & 2.49 & 0.50 & 2.89 & 0.03 & 2.00 & 0.09 & $0.0001^{*}$ \\
\hline Use of sleeping medication & & 1.89 & 0.95 & 2.62 & 0.08 & 1.00 & 0.06 & $0.0001^{*}$ \\
\hline Daytime dysfunction & & 1.99 & 0.44 & 2.00 & 0.07 & 1.83 & 0.08 & 0.520 \\
\hline PSQI total score & & 13.68 & 3.79 & 16.78 & 0.33 & 10.25 & 0.16 & $0.0001^{*}$ \\
\hline \multirow{2}{*}{$\begin{array}{l}\text { Sleep quality level } \\
\text { (percentage) }\end{array}$} & Good & 5 & & 4 & & 9 & & \multirow[t]{2}{*}{$0.001^{*}$} \\
\hline & Undesirable & 95 & & 96 & & 94 & & \\
\hline
\end{tabular}

PSQI: Pittsburgh Sleep Quality Index

${ }^{*} p<0.05$

Table 4. Mean scores of the dimensions of lifestyle among participants $(n=502)$

\begin{tabular}{|c|c|c|c|c|c|c|c|}
\hline \multirow[t]{3}{*}{ Dimensions } & \multirow{2}{*}{\multicolumn{2}{|c|}{ All participants $(n=420)$}} & \multicolumn{4}{|c|}{ Type of LBP } & \multirow[t]{3}{*}{ P-value } \\
\hline & & & \multicolumn{2}{|c|}{ Chronic $(n=210)$} & \multicolumn{2}{|c|}{ Acute/Sub-acute $(n=210)$} & \\
\hline & $M$ & $S D$ & $M$ & $S D$ & $M$ & $S D$ & \\
\hline Spiritual growth & 23.99 & 7.16 & 18.74 & 0.57 & 30.25 & 0.46 & $0.0001^{*}$ \\
\hline Health responsibility & 27.92 & 7.48 & 29.98 & 1.84 & 26.46 & 0.06 & $0.006^{*}$ \\
\hline Interpersonal relationships & 25.28 & 9.23 & 21.95 & 1.15 & 28.13 & 0.26 & $0.0001^{*}$ \\
\hline Stress management & 12.80 & 2.87 & 13.36 & 1.32 & 12.00 & 0.36 & $0.0001^{*}$ \\
\hline Physical activity & 11.18 & 5.44 & 7.27 & 0.07 & 16.81 & 0.59 & $0.0001^{*}$ \\
\hline Nutrition & 21.39 & 4.56 & 18.56 & 0.39 & 24.00 & 0.90 & $0.0001^{*}$ \\
\hline Lifestyle overall score & 123.58 & 28.68 & 104.12 & 3.04 & 140.67 & 1.01 & $0.0001^{*}$ \\
\hline
\end{tabular}

${ }^{*} p<0.05$ 
Table 5 - Risk factors affecting the chronicity of acute and sub-acute non-specific LBP using modified multiple logistic regression model

\begin{tabular}{|c|c|c|c|c|c|c|c|c|c|c|}
\hline \multirow[t]{2}{*}{ Parameter } & & \multirow[t]{2}{*}{$\beta$} & \multirow[t]{2}{*}{ SE } & \multirow[t]{2}{*}{ Wald } & \multirow[t]{2}{*}{ OR } & \multicolumn{2}{|c|}{$\begin{array}{l}95 \% \\
\text { confidence } \\
\text { interval for OR }\end{array}$} & \multirow[t]{2}{*}{$\begin{array}{l}\mathrm{P} \text { - } \\
\text { value }\end{array}$} & \multicolumn{2}{|l|}{$\mathrm{R}^{2}$} \\
\hline & & & & & & $\begin{array}{l}\text { Lower } \\
\text { Band }\end{array}$ & $\begin{array}{l}\text { Upper } \\
\text { Band }\end{array}$ & & Negelkerke & $\begin{array}{l}\text { Cox } \\
\& \\
\text { Snell }\end{array}$ \\
\hline \multirow[t]{8}{*}{ Demographic } & Weight & 0.061 & 0.020 & 2.13 & 1.06 & 0.99 & 1.14 & 0.019 & \multirow[t]{22}{*}{0.957} & \multirow[t]{22}{*}{0.846} \\
\hline & BMI & 0.082 & 0.060 & 7.02 & 1.08 & 1.00 & 1.14 & 0.001 & & \\
\hline & Job & 0.052 & 0.057 & 1.47 & 1.12 & 0.89 & 1.19 & 0.012 & & \\
\hline & $\begin{array}{l}\text { Type of } \\
\text { occupational } \\
\text { task }\end{array}$ & 0.357 & 0.019 & 20.02 & 1.43 & 1.01 & 1.74 & 0.001 & & \\
\hline & Previous LBP & 0.119 & 0.039 & 8.84 & 1.13 & 1.04 & 1.34 & 0.0001 & & \\
\hline & Work Shift & 0.068 & 0.035 & 4.32 & 1.08 & 1.05 & 1.20 & 0.001 & & \\
\hline & $\begin{array}{l}\text { Underlying } \\
\text { diseases }\end{array}$ & 0.068 & 0.009 & 3.21 & 1.07 & 0.97 & 1.19 & 0.001 & & \\
\hline & Income & -0.274 & 0.087 & 11.63 & 0.76 & 0.31 & 1.02 & 0.001 & & \\
\hline \multirow[t]{6}{*}{ Cognitive } & FABQ-PA & 0.294 & 0.018 & 16.09 & 1.35 & 0.89 & 1.58 & 0.001 & & \\
\hline & FABQ-W & 0.311 & 0.011 & 17.95 & 1.38 & .93 & 1.63 & 0.0001 & & \\
\hline & FABQ-Total & 0.343 & 0.060 & 19.44 & 1.41 & 1.02 & 1.66 & 0.0001 & & \\
\hline & TSK & 0.254 & 0.090 & 13.31 & 1.29 & 1.01 & 1.43 & 0.002 & & \\
\hline & PCS & 0.293 & 0.060 & 15.88 & 1.34 & 1.00 & 1.53 & 0.004 & & \\
\hline & PHQ & 0.918 & 0.080 & 24.96 & 2.50 & 1.12 & 3.19 & 0.0001 & & \\
\hline \multirow[t]{4}{*}{ Life Style } & $\begin{array}{l}\text { Lifestyle } \\
\text { overall score }\end{array}$ & -0.584 & 0.019 & 21.16 & 0.55 & 0.16 & 1.34 & 0.048 & & \\
\hline & $\begin{array}{l}\text { Health } \\
\text { responsibility }\end{array}$ & -0.193 & 0.030 & 7.39 & 0.82 & 0.69 & 1.09 & 0.001 & & \\
\hline & $\begin{array}{l}\text { Physical } \\
\text { activity }\end{array}$ & -0.279 & 0.040 & 12.21 & 0.75 & 0.58 & 1.02 & 0.0001 & & \\
\hline & $\begin{array}{l}\text { Interpersonal } \\
\text { relationships }\end{array}$ & -0.445 & 0.009 & 20.36 & 0.64 & 0.49 & 1.06 & 0.0001 & & \\
\hline \multirow[t]{3}{*}{ Sleep Quality } & $\begin{array}{l}\text { PSQI overall } \\
\text { score }\end{array}$ & 0.450 & 0.010 & 22.19 & 1.57 & 1.28 & 2.51 & 0.0001 & & \\
\hline & $\begin{array}{l}\text { Sleep } \\
\text { duration }\end{array}$ & 0.414 & 0.060 & 18.22 & 1.51 & 0.99 & 2.39 & 0.0001 & & \\
\hline & $\begin{array}{l}\text { Sleep } \\
\text { disturbances }\end{array}$ & 0.945 & 0.160 & 25.58 & 2.57 & 1.19 & 3.43 & 0.0001 & & \\
\hline RMDQ & & 0.226 & 0.190 & 10.84 & 1.25 & 0.88 & 2.07 & 0.0001 & & \\
\hline
\end{tabular}


B: Regression coefficient, SE: Standard Error, OR: Odds Ratio, FABQ-PA: Fear-Avoidance Beliefs Questionnaire (Physical Activity), FABQ-W: Fear-Avoidance Beliefs Questionnaire (Work), FABQ-Total: Fear-Avoidance Beliefs Questionnaire (Total Score), PHQ: Patient Health Questionnaire (Depression), PCS: Pain Catastrophizing Scale, TSK: Tampa Scale of Kinesiophobia, PSQI: Pittsburgh Sleep Quality Index, RMDQ: Roland-Morris Disability Questionnaire

Table 6 - Various fit indices of the obtained model

\begin{tabular}{|lll|}
\hline Model fit index & Acceptable range & Value \\
\hline$\chi 2 / d f$ & $<2.00$ & 0.343 \\
\hline RMSEA & $<0.07$ & 0.030 \\
\hline GFI & $>0.95$ & 0.983 \\
\hline CFI & $>0.95$ & 0.993 \\
\hline IFI & $>0.95$ & 0.978 \\
\hline
\end{tabular}

$\mathrm{CFI}=$ comparative fit index; GFI = goodness-of-fit index; IFI = incremental fit index; RMSEA = root mean square error of approximation.

Table 7 - Significance value of each path in the obtained model.

\begin{tabular}{|c|c|c|c|c|}
\hline \multicolumn{2}{|l|}{ Path } & \multirow[t]{2}{*}{ Standardized path coefficient } & \multirow[t]{2}{*}{ Standard Error } & \multirow[t]{2}{*}{ P-value } \\
\hline From & To & & & \\
\hline Lifestyle & Disability & -0.68 & 0.013 & $<0.001$ \\
\hline Lifestyle & FABQ-PA & -0.20 & 0.003 & $<0.001$ \\
\hline Lifestyle & $\mathrm{PHQ}$ & -0.76 & 0.011 & $<0.001$ \\
\hline Lifestyle & PSQI & -0.36 & 0.005 & $<0.001$ \\
\hline Lifestyle & Pain severity & -0.49 & 0.004 & $<0.001$ \\
\hline Disability & LBP & 0.38 & 0.007 & $<0.001$ \\
\hline FABQ-PA & LBP & 0.33 & 0.005 & $<0.001$ \\
\hline PHQ & LBP & 0.68 & 0.029 & $<0.001$ \\
\hline PSQI & LBP & 0.39 & 0.015 & $<0.001$ \\
\hline Pain severity & LBP & 0.27 & 0.031 & $<0.001$ \\
\hline
\end{tabular}

FABQ-PA: Fear-Avoidance Beliefs Questionnaire (Physical Activity), PHQ: Patient Health Questionnaire (Depression), PSQI: Pittsburgh Sleep Quality Index, LBP: Low Back Pain.

\section{Figures}




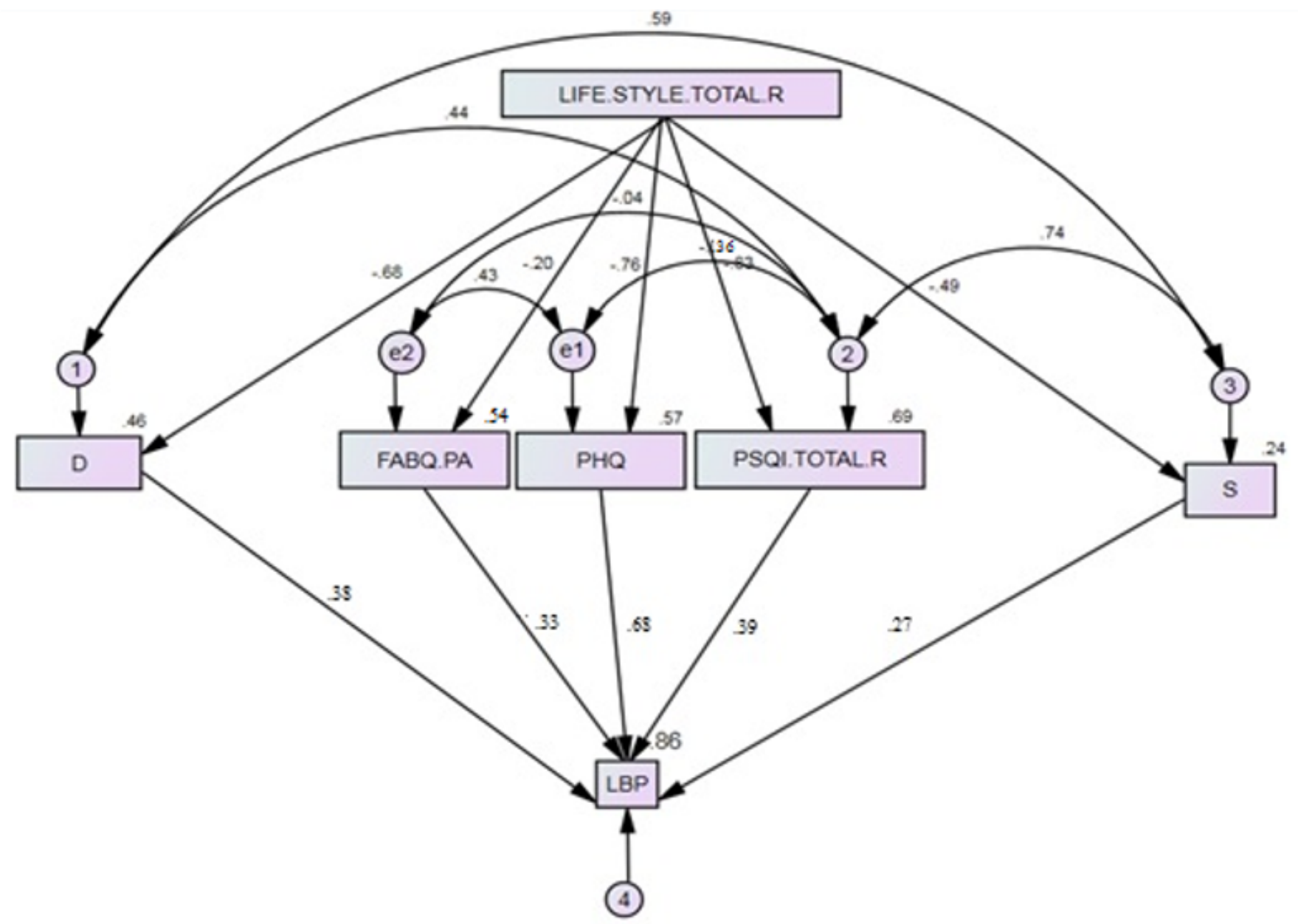

Figure 1

The final obtained path analysis model FABQ-PA: D: Disability, S: Pain severity, Fear-Avoidance Beliefs Questionnaire (Physical Activity), PHQ: Patient Health Questionnaire (Depression), PSQI: Pittsburgh Sleep Quality Index, LBP: Low Back Pain. 